\title{
Ocorrência de Blastocerus dichotomus (Mammalia, Cetartiodactyla, Cervidae) no Município de João Pinheiro: um novo registro de uma população provavelmente residual e ameaçada no Cerrado de Minas Gerais, Brasil.
}

\author{
Adriano Lima Silveira ${ }^{1} \&$ Sandro Aparecido Pacheco ${ }^{2}$
}

${ }^{1}$ Biótica Estudos Ambientais. Caixa Postal 2020, CEP 30270-970, Belo Horizonte, MG, Brasil. E-mail: biosilveira@ yahoo.com.br.

2E-mail: sandrodf83@hotmail.com.

Abstract. Occurrence of Blastocerus dichotomus (Mammalia, Artiodactyla, Cervidae) in João Pinheiro: a new record of a probable residual and threatened population in Cerrado of Minas Gerais, Brazil. The Marsh Deer or Suçuapara, Blastocerus dichotomus, presents reduced, fragmented current geographical distribution in relation to the original distribution. In State of Minas Gerais it has potential occurrence in some areas, but only rare confirmed record. The species is Critically Endangered in Minas Gerais, and Vulnerable in Brazil. We present a new record of B. dichotomus in Cerrado, in the Municipality of João Pinheiro, Minas Gerais Northwest. Specimens were recorded with camera traps, in a remnant of Vereda on Paracatu River floodplain. This study also obtained indirect records of the species occurrence. Due to the richness of flooded environments it is possible that $B$. dichotomus occurs in other areas of João Pinheiro, especially along the Campinas and other floodplains of rivers, which is reinforced by reports of local people. The local population of $B$. dichotomus was considered probably residual and threatened, mainly due to degradation of the natural environments, hunting and the presence of cattle. Current relevant impacts are the expansion of large-scale monocultures and future impoundments of rivers. Measures to protect the local population of $B$. dichotomus are necessary and urgent, such as inventories and other studies, protection of natural remnants, recovery of degraded areas, and especially the creation of Conservation Units, non-existent in João Pinheiro.

Keywords: Blastocerus dichotomus; Cerrado; Minas Gerais; geographic distribution; threatened species.

Resumo. O cervo-do-pantanal ou suçuapara, Blastocerus dichotomus, apresenta distribuição geográfica atual reduzida e fragmentada em relação à distribuição original e, no Estado de Minas Gerais, possui ocorrência potencial em algumas áreas, mas apenas raros registros confirmados. A espécie encontra-se Criticamente em Perigo em Minas Gerais e Vulnerável no Brasil. Apresenta-se um novo registro de B. dichotomus no Cerrado, no Município de João Pinheiro, Noroeste de Minas Gerais. Exemplares foram registrados com o uso de armadilhas fotográficas, em um remanescente de Vereda na várzea do rio Paracatu. Adicionalmente, também foram obtidos registros indiretos da ocorrência da espécie. Em função da riqueza de ambientes alagados é possível que $B$. dichotomus ocorra em outras áreas de João Pinheiro, especialmente ao longo das Campinas e demais várzeas de rios, o que é reforçado por relatos de moradores locais. A população local foi considerada provavelmente residual e ameaçada, devido principalmente à degradação dos ambientes naturais, caça e presença de bovinos. Impactos atuais relevantes são a expansão de 
74. SILVEIRA \& PACHECO

monoculturas em larga escala e futuros represamentos de rios. São necessárias e urgentes medidas para a proteção da população local de $B$. dichotomus, tais como inventários e outros estudos, proteção de remanescentes naturais, recuperação de áreas degradadas e, principalmente, a criação de Unidades de Conservação, inexistentes em João Pinheiro.

Palavras-chave: Blastocerus dichotomus; Cerrado; Minas Gerais; distribuição geográfica; espécie ameaçada.

\section{INTRODUÇÃO}

O cervídeo Blastocerus dichotomus Illieger, 1815 (Mammalia, Artiodactyla, Cervidae), mais comumente conhecido como cervo-do-pantanal, possuía distribuição geográfica ampla pela América do Sul, ao longo das várzeas e planícies de inundação dos grandes rios a leste dos Andes, sul da Amazônia e norte dos Pampas e Patagônia, estendendo-se desde o sudeste do Peru até o noroeste do Uruguai e região do delta do rio da Prata (TIEPOLO \& TOMAS, 2006). Esta distribuição abrangia grande parte do bioma Cerrado, incluindo a porção da bacia do rio São Francisco em Minas Gerais, onde B. dichotomus é popularmente conhecida como suçuapara ou veado-galheiro.

Atualmente $B$. dichotomus apresenta distribuição restrita a áreas úmidas da Bolívia, Paraguai, Argentina e Brasil, a qual se encontra bastante reduzida e fragmentada, constituída, em sua maioria, por populações residuais (DuARTE, 2008; TIEPolo \& TOMAS, 2006). Maiores concentrações populacionais da espécie persistem apenas no Pantanal (Mato Grosso e Mato Grosso do Sul), ilha do Bananal e rio Araguaia (Mato Grosso e Tocantins), rio Guaporé (Rondônia) e várzeas remanescentes do rio Paraná (Mato Grosso do Sul, Paraná e São Paulo) (DuARTE, 2008; DuARTE et al., 2012a). áreas de vida potenciais para o suçuapara. A Vereda corresponde a uma paisagem ocorrente em solos Hidromórficos, saturados a maior parte do ano, sendo composta pela palmeira arbórea buriti (Mauritia flexuosa L. f.) emergente em meio a agrupamentos mais ou menos densos de espécies arbustivo-herbáceas, circundada por Campo Limpo Úmido e geralmente acompanhando linhas de drenagens (RIBEIRO \& WALTER, 1998).

Blastocerus dichotomus possui grande porte, chegando $1,27 \mathrm{~m}$ de altura, 1,91 m de comprimento e $125 \mathrm{~kg}$ de massa corporal, e os machos possuem galhada grande e ramificada, que pode chegar a 60 $\mathrm{cm}$ de comprimento e que normalmente apresenta cinco extremidades (PINDER \& GROSSE, 1991). A espécie vive em áreas abertas alagadas, incluindo várzeas de grandes rios e seus tributários, além de frequentar também matas ciliares (DUARTE, 2008; DuARTE et al., 2012a). Geralmente é solitária ou pode formar pequenos grupos (SCHALLER \& VASCONCELlos, 1978). Nos alagados o suçuapara alimenta-se de plantas aquáticas ou tolerantes a inundações sazonais e solos encharcados (TOMAS \& SALIS, 2000). Grande parte do conhecimento disponível sobre $B$. dichotomus refere-se a grandes populações ocorrentes no Pantanal (ver dados citados por TIEPOLO \& TOMAS, 2006), havendo carência de informações sobre populações residuais da bacia do São Francisco no Cerrado. 
ameaçado de extinção no Brasil, na categoria Vulnerável - VU, segundo a lista oficial da fauna brasileira ameaçada publicada em 2003 (DUARTE, 2008; MMA, 2003). Em recente reavaliação do estado de conservação da espécie, $B$. dichotomus permaneceu na mesma categoria, com base no critério que considerou declínio populacional passado e projeção de declínio futuro (DUARTE et al., 2012a; MMA, 2014). A espécie necessita do ambiente de várzea para sobreviver e sofreu uma intensa redução populacional no último século, devido à perda de hábitat, caça e doenças de bovinos (DUARTE, 2008). A alteração e a eliminação de hábitats ocorreram em função do avanço das fronteiras agrícolas e urbanas e, mais recentemente, dos represamentos das usinas hidrelétricas (DUARTE, 2008).

No Estado de Minas Gerais B. dichotomus também foi considerado ameaçado, mas na categoria Criticamente em Perigo - CR (COPAM, 2010; ChiARello et al. , 2008). Embora Minas Gerais abrigue vários rios de médio e grande porte, a maior parte das várzeas que os acompanham foi degradada, drenada, transformada em áreas de cultivo ou submersas por reservatório de hidrelétricas, o que causou o quase desaparecimento do suçuapara no estado (CHIARELLo et al., 2008). As principais ameaças à espécie em Minas Gerais são a caça e a destruição, degradação e fragmentação do Cerrado, além da presença de gado doméstico, o qual pode ser transmissor de doenças (CHIARELLO et al., 2008).

Registros tanto históricos como recentes de $B$. dichotomus em Minas Gerais são escassos. A espécie foi considerada extinta nas planícies inundáveis do rio São Francisco por ToMAS et al. (1997). No entanto, de acordo com a última avaliação da fauna ameaçada de extinção em Minas Gerais, $B$. dichotomus ocorre no extremo noroeste do estado, no Parque Nacional (P. N.) Grande Sertão Veredas, onde ainda há grandes extensões de Veredas bem preservadas, e também há evidências de sua ocorrência no P. N. Cavernas do Peruaçu (Norte de Minas) e na Fazenda Brejão ("Triângulo Mineiro") (CHIARELlo et al., 2008). Anteriormente a essa avaliação, a presença de $B$. dichotomus no $P$. N. Cavernas do Peruaçu já havia sido mencionada no Plano de Manejo da unidade (IBAMA, 2005), com base em indícios ou vestígios indiretos obtidos em campo e entrevistas, e esse mesmo registro foi em seguida reportado por FERREIRA et al. (2011).

\section{Em publicação do Instituto Estadual} de Florestas sobre a fauna nas Unidades de Conservação de Minas Gerais (AlMEIdA, 2011) foram apresentadas, em representação em mapa, ocorrências de $B$. dichotomus em seis Unidades de Conservação - na região norte do estado, bacia do São Francisco: 1) P. N. Grande Sertão Veredas, 2) Parque Estadual (P. E.) da Mata Seca, 3) P. N. Cavernas do Peruaçu, 4) P. E. Serra das Araras; no sudoeste do estado, bacias do São Francisco e Paraná: 5) P. N. da Serra da Canastra; na porção centro-leste da Cadeia do Espinhaço, bacia do Jequitinhonha: 6) P. E. da Serra Negra. As cinco primeiras unidades situam-se nos domínios do Cerrado ou em área de transição deste com a Caatinga e nas proximidades do limite oriental da distribuição potencial de B. dichotomus, segundo DUARTE et al. (2012a) e PIovezAn et al. (2010). Já o P. E. da Serra Negra está distante desse limite e em uma região montanhosa na transição entre o Cerrado e Mata Atlântica, onde não ocorrem os tipos de várzeas alagadas onde vive o suçuapara, o que levanta a necessidade de 
confirmação do registro.

Os dados apresentados no estudo de ALMEIDA (2011) provêm de uma compilação de relatórios técnicos, planos de manejo de Unidades de Conservação e outros estudos, não sendo especificados os métodos de registros ou apresentadas as evidências que os comprovem, de modo que devem ser considerados com cautela. Somente o registro no P. N. Grande Sertão Veredas foi mencionado em estudos posteriores, sobre avaliação do estado de conservação de $B$. dichotomus (DUARTE, 2008; DUARTE et al., 2012a; DUARTE et al., 2012b), os quais também não consideraram os registros no P. N. Cavernas do Peruaçu (IBAMA, 2005; FerReira et al., 2011).

O estado de ameaça de $B$. dichotomus e a carência de conhecimento sobre suas populações residuais ressaltam a importância de divulgação de registros geográficos da espécie, especialmente de populações remanescentes em regiões distantes das áreas que abrigam as maiores concentrações. No presente trabalho apresenta-se um novo registro do suçuapara no Cerrado de Minas Gerais.

\section{MAterial e Métodos}

Os dados aqui apresentados são parte um estudo mais amplo de levantamento dos mamíferos de médio e grande porte no Município de João Pinheiro, situado no Noroeste de Minas Gerais. João Pinheiro abriga remanescentes naturais de diversas fitofisionomias do bioma Cerrado. Durante atividades de campo foram identificados remanescentes expressivos de Campo Limpo, Campo Sujo, Parque de Cerrado, Cerrado sentido restrito, Cerradão, Mata Seca Decídua, Mata Ciliar,
Mata de Galeria e Vereda, além de subtipos dessas feições (senso RIBEIRO \& WALTER, 1998).

Dentre essas paisagens, destacam-se duas regiões ecológicas. A primeira corresponde às várzeas que acompanham os vales dos principais rios da região, onde há Matas Ciliares, Veredas, alagados temporários e lagoas marginais naturais. Os rios que possuem tais várzeas são o Paracatu e seus afluentes: os rios da Prata (Figura 1), Caatinga, do Sono, Feio e Verde, além de tributários menores. Os rios da Prata e Paracatu e as fozes dos rios Caatinga e do Sono abrigam os trechos mais expressivos. A outra paisagem corresponde a extensas planícies localmente chamadas de Campinas (Figuras 1 e 2), que se estendem a leste dos rios Paracatu e da Prata e a oeste da Serra de Brasilândia (ou Serra da Maravilha), e englobam os rios Feio e Verde, os ribeirões da Mutuca e da Anta (ou Vereda da Anta) e tributários menores. Essas planícies são ricas em ambientes aquáticos, tais como nascentes, alagados e lagoas naturais perenes e temporárias, e são cobertas por mosaicos vegetacionais de Parque de Cerrado, Campo Cerrado e Vereda, especialmente o primeiro tipo. Nas adjacências dos dois mosaicos há formações de Cerrado sentido restrito e Cerradão.

Foram obtidos registros com o uso de uma armadilha fotográfica digital LTL Acorn, modelo 5210A, a qual foi programada para o funcionamento contínuo. A câmera foi instalada em alguns pontos ao longo de uma várzea, totalizando 65 diascâmera de esforço amostral. No ponto dos registros a câmera foi instalada no período de 04 a 25 de maio de 2014, com um esforço de 21 dias-câmera. A instalação ocorreu em frente a uma cerca de propriedade, em um suposto local de travessia de animais. A área do estudo foi escolhida com base 


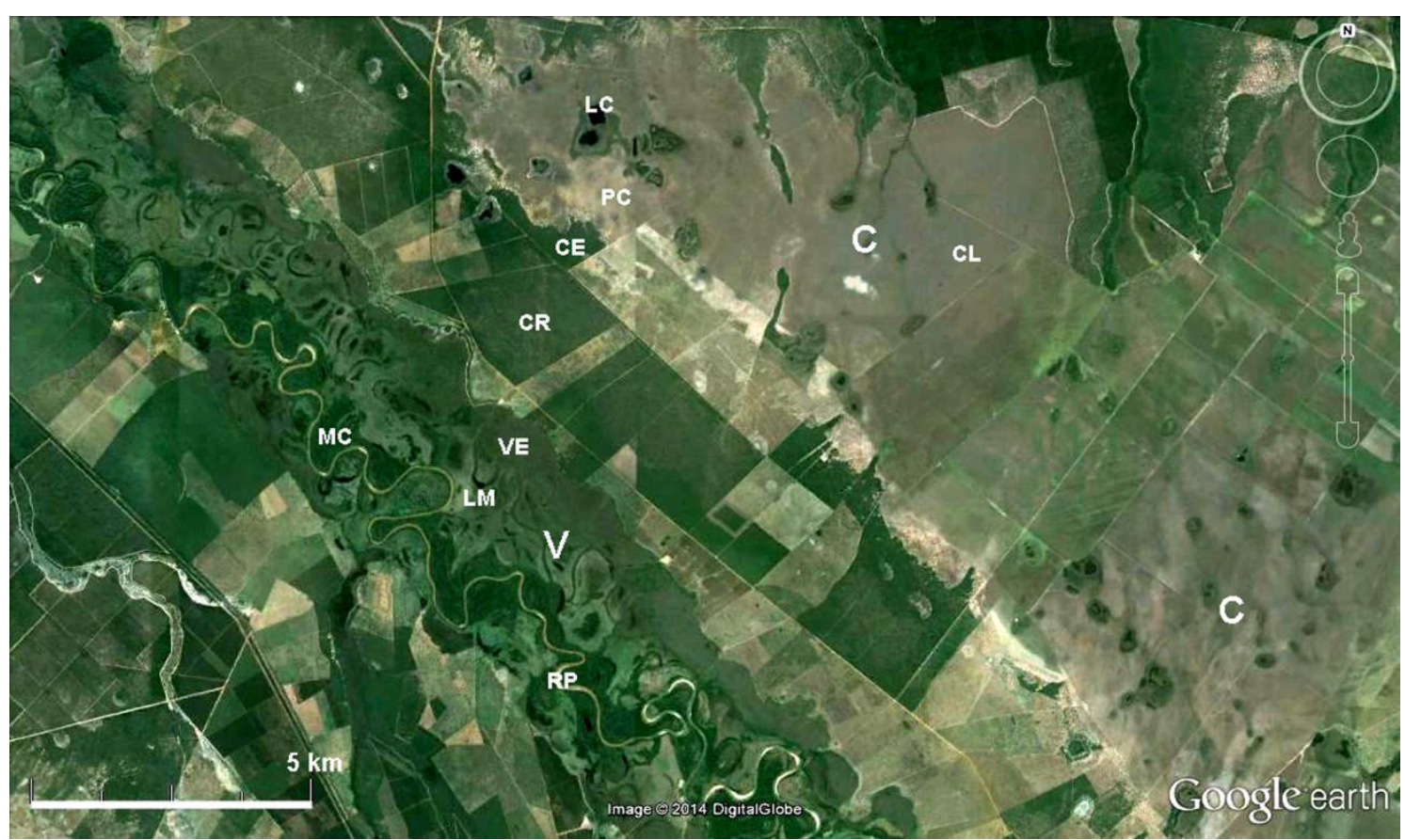

Figura 1. Imagem de satélite extraída do programa Google Earth 7.1.2.2041 (imagens múltiplas datadas de 22/07/2010 a 18/12/2012), mostrando regiões ecológicas das Várzeas (V) e Campinas (C) em João Pinheiro. Mosaico de remanescentes naturais: RP) rio da Prata, VE) Vereda, MC) Mata Ciliar, LM) lagoa marginal, CL) Campo Limpo, PC) Parque de Cerrado, LC) lagoa natural de campina, CE) Cerradão, CR) Cerrado sentido restrito. A imagem mostra parte do complexo de cerca de $25 \mathrm{~km}$ de várzea conservada do rio da Prata.



Figura 2. Paisagem das Campinas em João Pinheiro - 1) Parque de Cerrado, 2) lagoa natural.

em relatos de um morador local sobre a ocorrência do suçuapara.

Também foi considerado um registro ocasional por encontro de galhada da espécie e foram realizadas entrevistas com moradores de diversas áreas rurais de João Pinheiro, visando identificar locais de possível ocorrência de $B$. dichotomus.

\section{RESULTADOS}

Foram obtidas fotografias e filmagens de três indivíduos de Blastocerus dichotomus na 
Fazenda Remanso do Rio Paracatu (FRRP), uma propriedade particular às margens do Rio Paracatu,

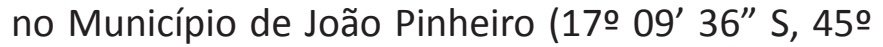
50' 09" O, $492 \mathrm{~m}$ alt.). O ponto de registro situa-se a $400 \mathrm{~m}$ a sul do Paracatu e $400 \mathrm{~m}$ a leste/sudeste da foz do rio Catinga com o Paracatu, onde se localiza a vila do Distrito de Caatinga.

Os registros foram obtidos nos dias 06 a 18 de maio de 2014, em período noturno nos horários de 19:27 a 02:44 h, em um total de quatro registros correspondentes a três indivíduos (um deles fotografado/filmado duas vezes), sendo dois machos e uma fêmea, todos adultos (Figura 3). Os animais apareceram caminhando lentamente, pastando ou coçando-se e um deles (fêmea) exibiu o peito parasitado por grande número de carrapatos.

Um macho exibiu galhada maior, com cinco pontas desenvolvidas no lado direito e quatro pontas desenvolvidas mais uma vestigial no esquerdo. Já o segundo macho exibiu galhada

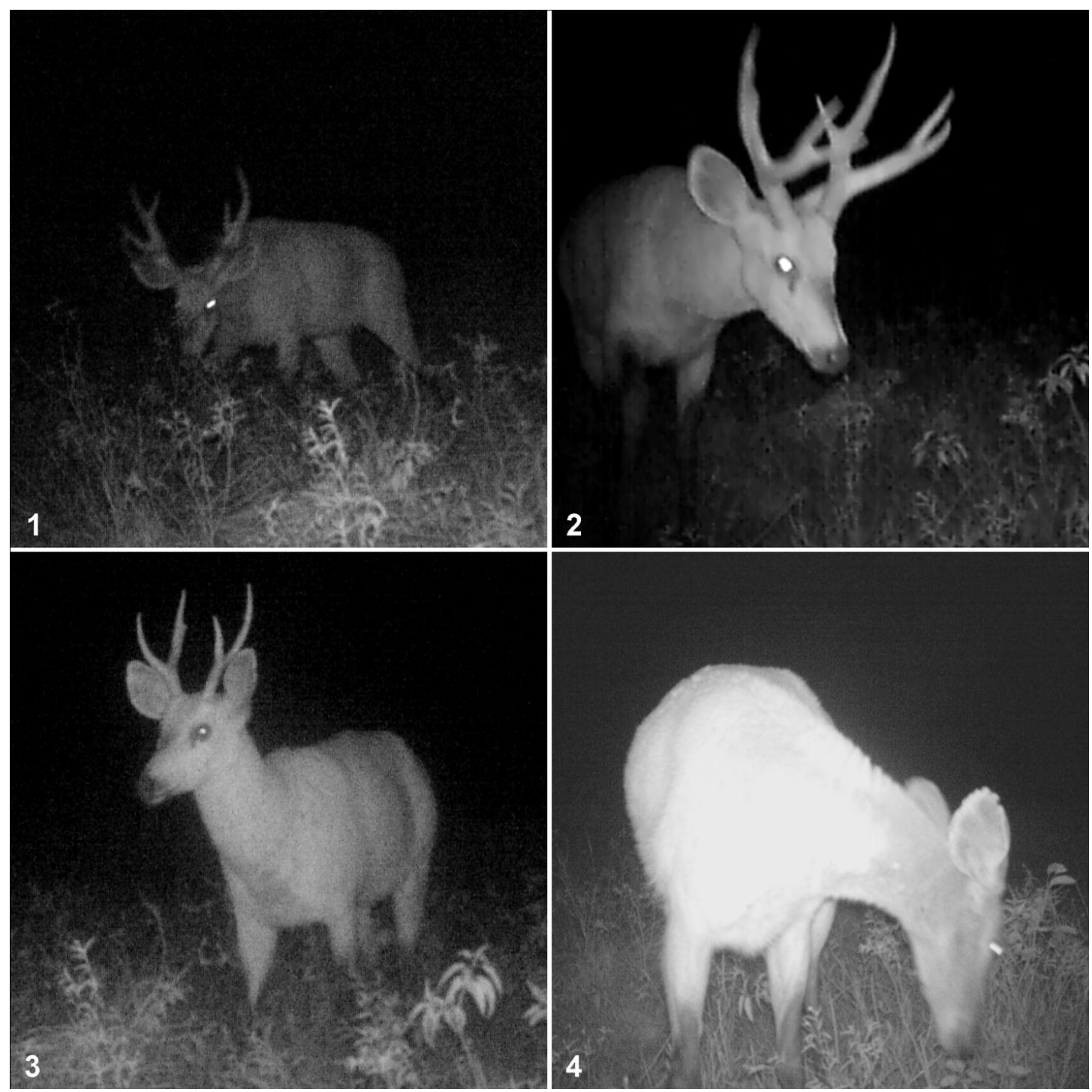

Figura 3. Indivíduos de Blastocerus dichotomus registrados por armadilha fotográfica em João Pinheiro, na Fazenda Remanso do Rio Paracatu. - 1, 2) primeiro macho, 3) segundo macho, 4) fêmea. 
com duas pontas mais uma vestigial no lado direito e duas pontas no lado esquerdo. Considerou-se que esses exemplares pertencem a uma população provavelmente residual de $B$. dichotomus, que utiliza a várzea do Paracatu como área de vida.

O local de registro corresponde a uma extensa Vereda em solo Hidromórfico na várzea do Paracatu (Figura 4), separada deste rio por uma faixa de mata ciliar remanescente. A Vereda possui formato semicircular, com uma porção de cerca de $3,8 \mathrm{~km}$ por $1,2 \mathrm{~km}$ em melhor estado de conservação, compondo uma várzea de cerca de 6 $\mathrm{km}$ de extensão e demais regiões bem alteradas por pastagens artificiais. A porção melhor conservada também possui alterações, estando cortada por uma estrada e diversos trilhos, mas com áreas preservadas de buritizal, Campo Limpo Úmido, lagoas naturais e alagados rasos. A área situa-se em uma matriz de ambientes alterados que incluem pastagens artificiais, silvicultura de eucalipto, outras monoculturas, formações de Cerrado sentido restrito remanescentes e em regeneração, e Veredas conservadas e alteradas (Figura 5).

Também foi obtido um registro indireto, de ocorrência mais antiga de $B$. dichotomus em João Pinheiro. Trata-se de uma galhada de um macho, com $51 \mathrm{~cm}$ de comprimento e $38 \mathrm{~cm}$ de largura (Figura 6), encontrada em meados de 1997, nas proximidades da ponte da BR 040 sobre o rio da Prata (17 42' 06" S, 46 20' 28" O, $544 \mathrm{~m}$ alt.), próximo à divisa com o Município de Lagoa Grande. A galhada encontrava-se na margem de uma Vereda bem conservada em formato semicircular e com cerca de $4 \mathrm{~km}$ de extensão, na várzea do

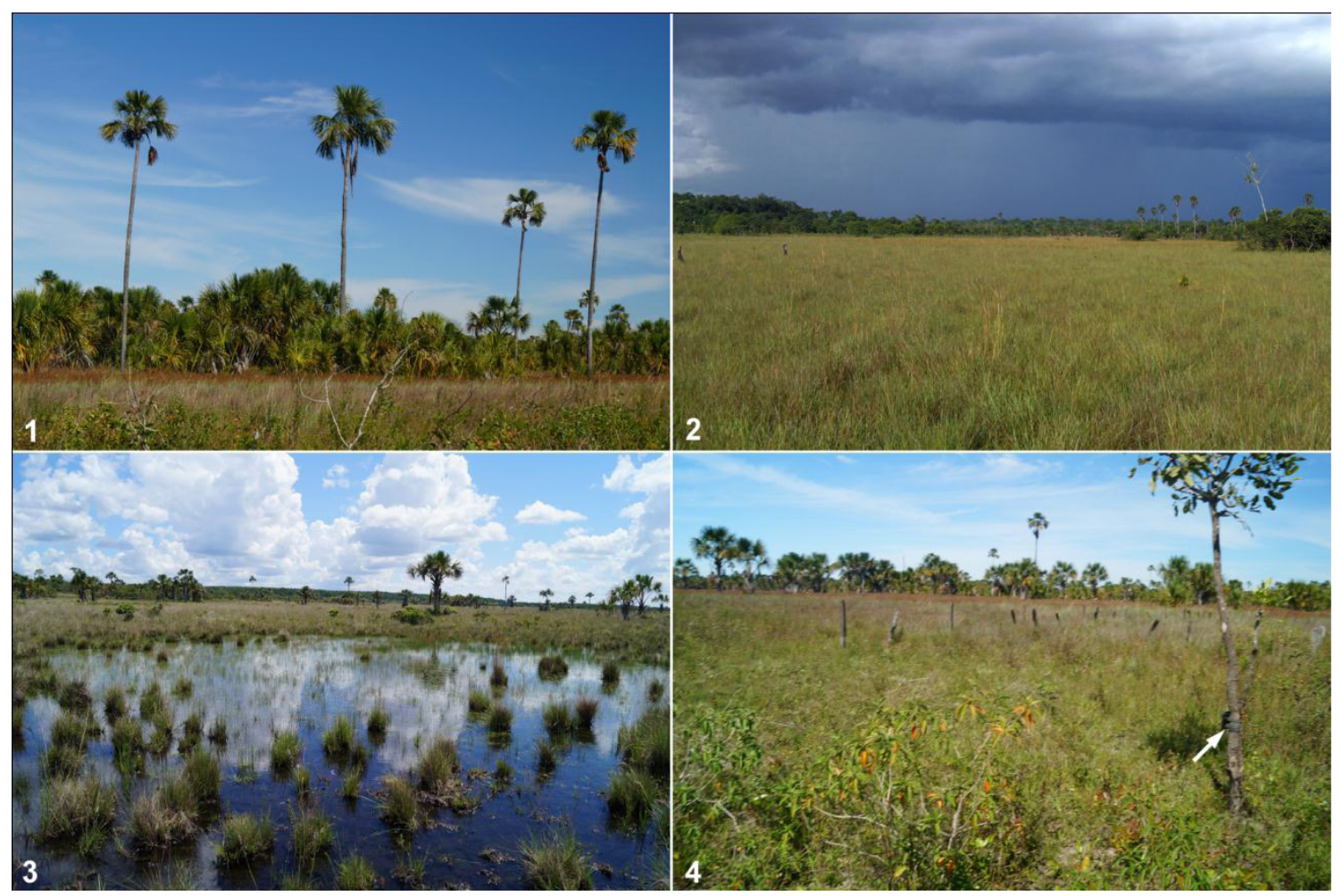

Figura 4. Vereda onde Blastocerus dichotomus foi registrado por fotografias na Fazenda Remanso do Rio Paracatu, em João Pinheiro - 1) buritizal, 2) Campo Limpo Úmido, 3) lagoa natural temporária, 4) ponto de registro em campo com buritizal ao fundo; a seta indica a armadilha fotográfica afixada em uma pequena árvore. 

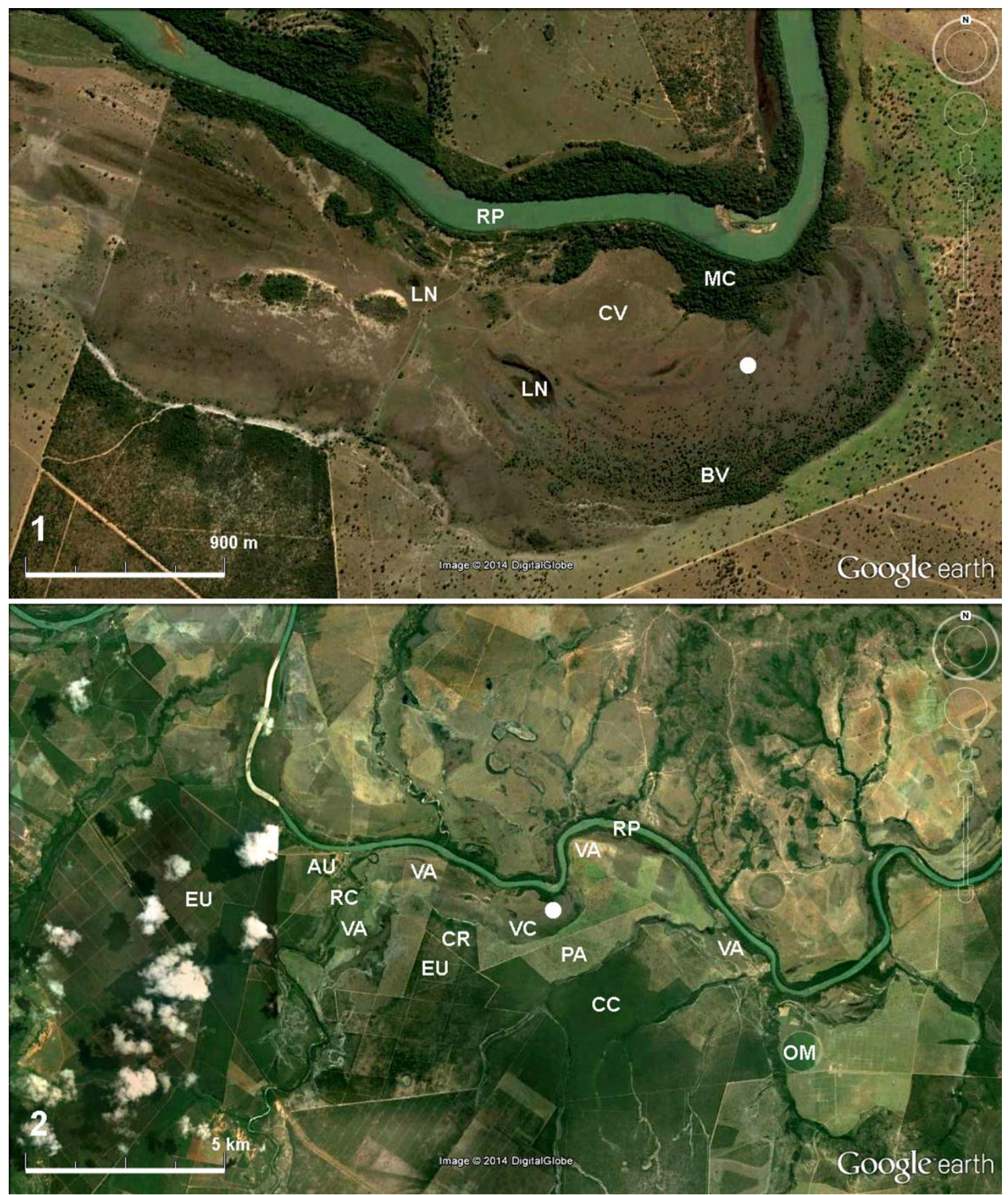

Figura 5. Imagem de satélite extraída do programa Google Earth 7.1.2.2041 (datada de 07/06/2003) mostrando a paisagem heterogênea no local de registro fotográfico de Blastocerus dichotomus na Fazenda Remanso do Rio Paracatu (1), em João Pinheiro, e na região de entorno (2). O ponto branco representa o local de registro da espécie. RP) rio Paracatu, RC) rio Caatinga, VC) Vereda conservada, VA) Vereda alterada, BV) buritizal de Vereda, CV) Campo Limpo Úmido de Vereda, MC) Mata Ciliar, LN) lagoa natural, CC) Cerrado sentido restrito conservado, CR) Cerrado sentido restrito em regeneração, PA) pastagem artificial, EU) eucaliptal, OM) outras monoculturas (pivô central), AU) área urbana no Distrito de Caatinga. A alteração ambiental atual é maior que a evidenciada na imagem. 
Prata (Figura 7). A Vereda localiza-se adjacente a uma área de Cerrado sentido restrito atualmente impactada e parcialmente convertida em pastagem para pecuária, nas proximidades da rodovia BR

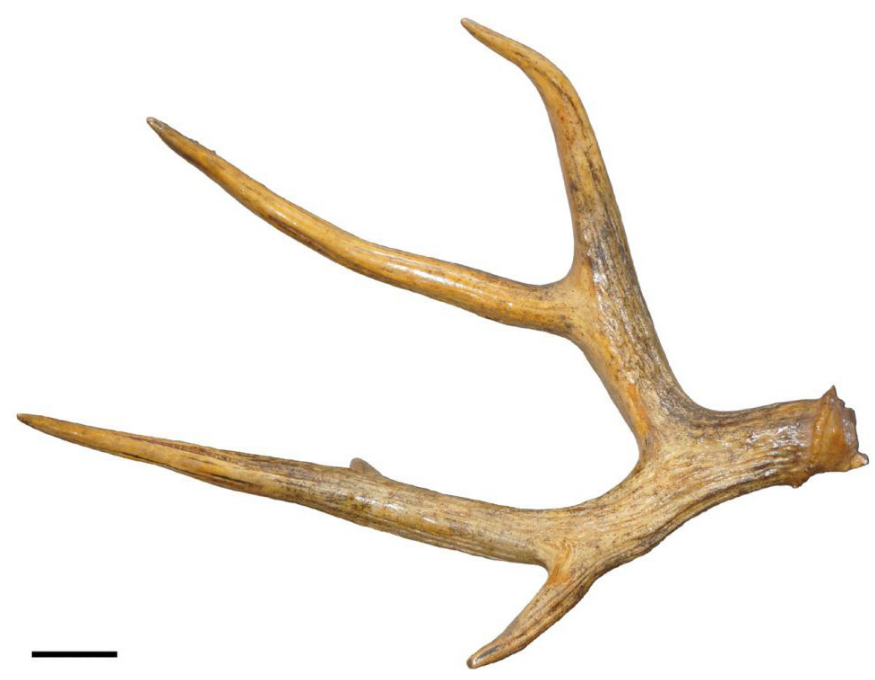

Figura 6. Galhada de macho de Blastocerus dichotomus encontrada na margem de uma Vereda na várzea do rio da Prata, nas proximidades da ponte da BR 040, João Pinheiro, MG. Barra de escala: $5 \mathrm{~cm}$.
040 e do vilarejo Ruralminas. Neste local não são conhecidas evidências de ocorrência atual de $B$. dichotomus.

Por fim, outro registro indireto foi obtido em entrevista com terceiro. Foi relatado o encontro relativamente recente com exemplares de suçuapara

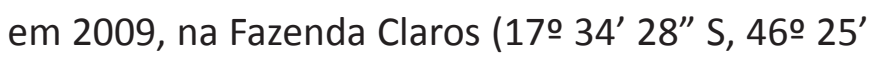
$16 " \mathrm{O}, 530 \mathrm{~m}$ alt. - coordenadas aproximadas). Tal relato foi considerado confiável, por parte de terceiro que sabe reconhecer a espécie. No referido ano, exemplares foram observados algumas vezes no mesmo local. Em uma das observações foi possível a contagem de cinco exemplares, enquanto que em outra observação, três animais foram vistos pela manhã alimentando-se de buritis, frutos da palmeira típica das Veredas. O registro ocorreu em uma extensa Vereda associada a lagoas marginais naturais, na várzea do rio da Prata (Figura

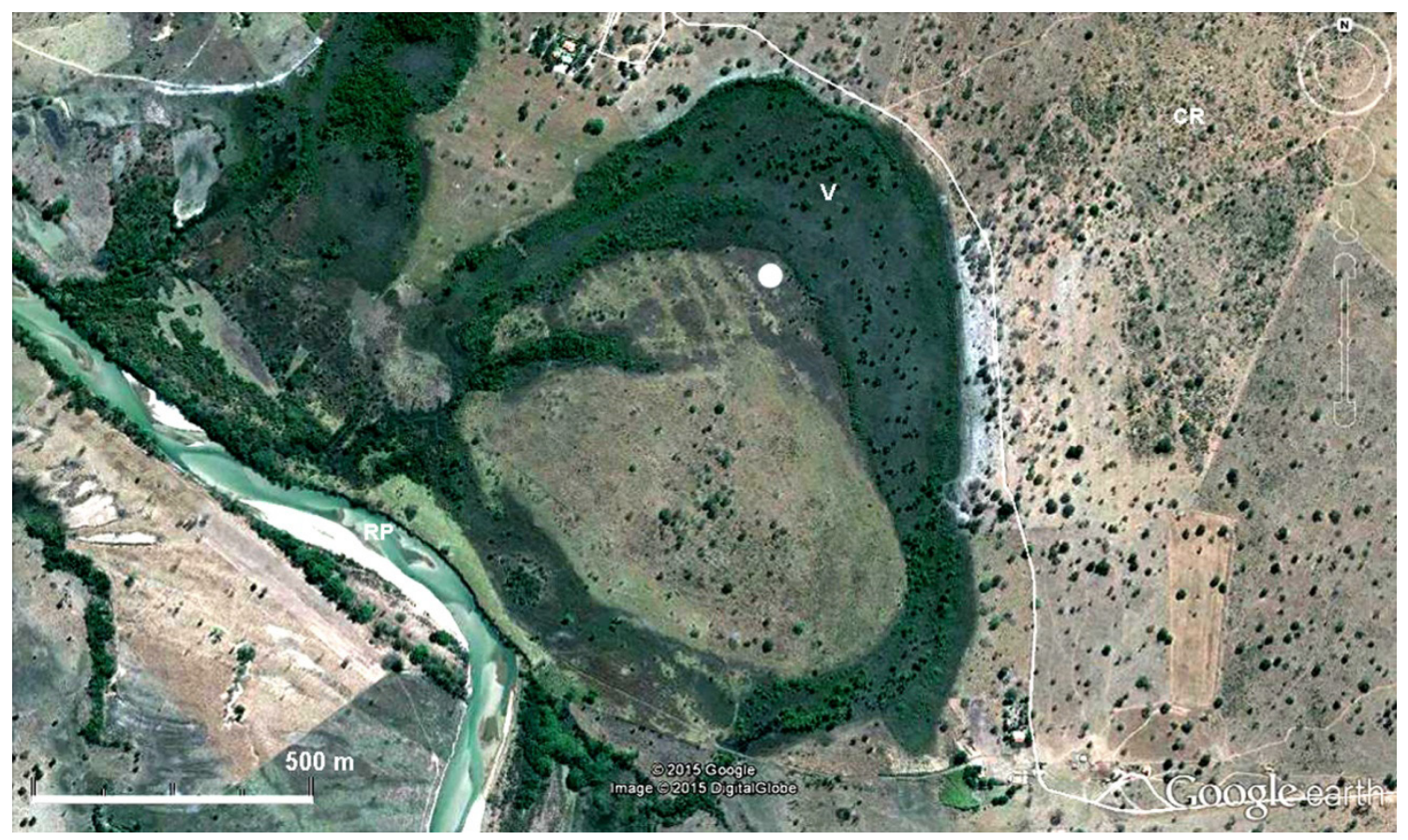

Figura 7. Imagem de satélite extraída do programa Google Earth 7.1.2.2041 (datada de 24/08/2010) mostrando a paisagem onde foi encontrada uma galhada de Blastocerus dichotomus nas proximidades da ponte da BR 040, na várzea do rio da Prata, João Pinheiro. O ponto branco representa o local de encontro da galhada. RP) rio da Prata, V) Vereda, CR) Cerrado sentido restrito em regeneração. 


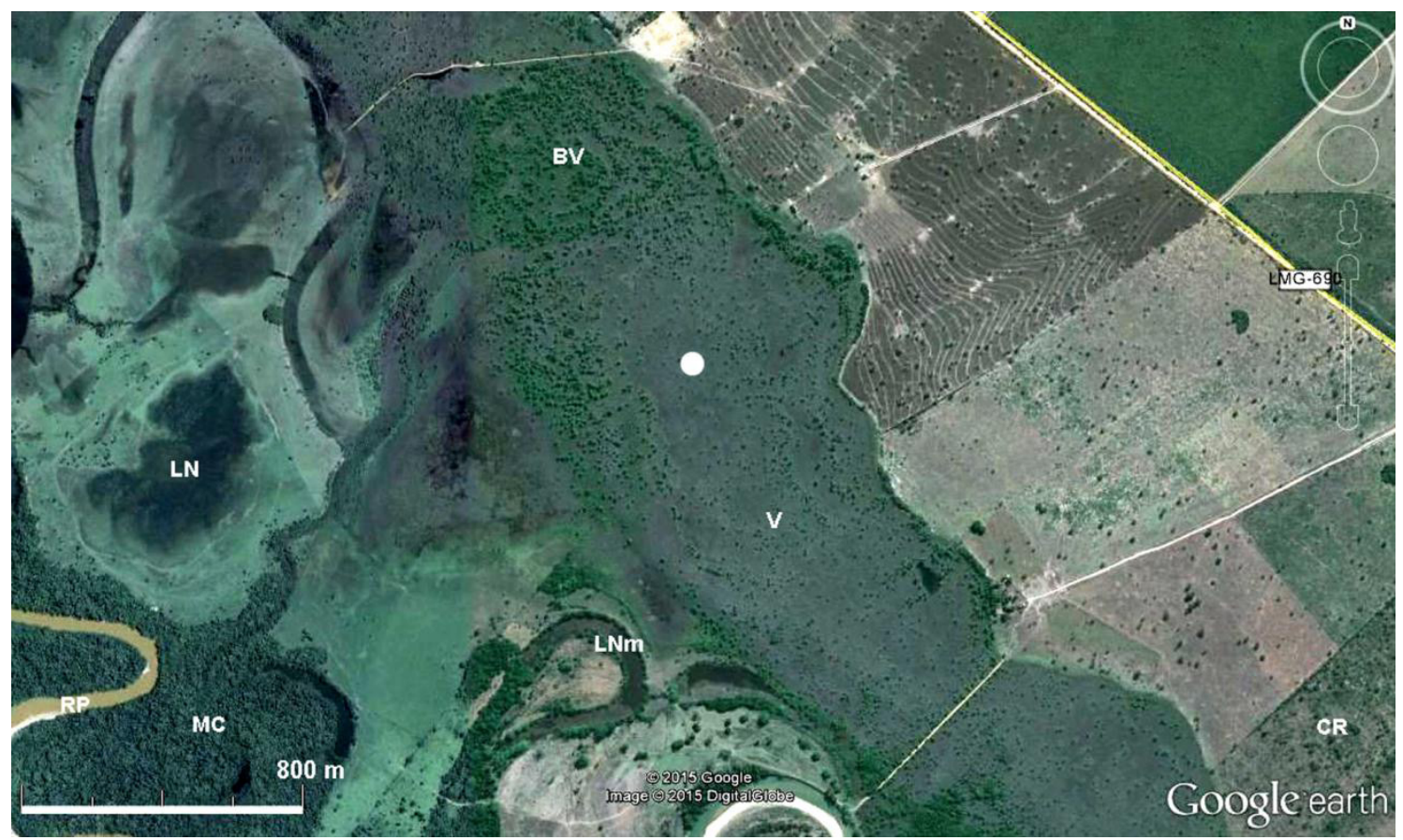

Figura 8. Imagem de satélite extraída do programa Google Earth 7.1.2.2041 (datada de 22/07/2010) mostrando a paisagem onde foram obtidos registros visuais de Blastocerus dichotomus por terceiro na várzea do rio da Prata, Fazenda Claros, João Pinheiro. O ponto branco representa o local de registro da espécie. RP) rio da Prata, V) Vereda, BV) buritizal de Vereda, MC) Mata Ciliar, CR) Cerrado sentido restrito em regeneração, LN) lagoa natural, LNm) lagoa natural meândrica. A imagem mostra parte do complexo de cerca de $25 \mathrm{~km}$ de várzea conservada do rio da Prata.

8). A localidade compõe um complexo de cerca de $25 \mathrm{~km}$ de grandes Veredas, muitas lagos marginais meândricas, brejos e extensos remanescentes de Mata Ciliar ao longo da várzea do Prata, na divisa com o Município de Lagoa Grande (Figura 1). A várzea encontra-se preservada, com reduzidas intervenções antrópicas. O complexo é contínuo com remanescentes de Cerradão e Cerrado sentido restrito, parcialmente alterados, e em seguida com os campos naturais das Campinas. O local da observação situa-se a cerca de $16 \mathrm{~km}$ a noroeste do ponto de encontro da galhada, também na várzea do Prata.

Este complexo descrito corresponde ao mais importante remanescente de várzea do rio da Prata, em toda a sua extensão, considerando a heterogeneidade ambiental e o estado de conservação das ambientes naturais.
Provavelmente, essa várzea também possui relevância no contexto da bacia do São Francisco.

Ainda considerando as entrevistas com moradores da zona rural de João Pinheiro, foram obtidos alguns relatos da ocorrência do suçuapara (ou veado-galheiro) na região das Campinas, especialmente na Fazenda Fruta D'Anta (170 28' 08" S, 460 12' 06" O, $552 \mathrm{~m}$ alt. - coordenadas de referência), situada nas proximidades do rio Feio (Figura 9). A maior parte dos relatos referiu-se a décadas passadas, quando a espécie teria sido abundante. Na Fazenda Fruta D’Anta obteve-se um relato de observação de dois exemplares da espécie ocorrido em 2010.

Considerando possíveis ameaças locais ao suçuapara, alguns entrevistados relataram a caça à espécie nas planícies alagadas da região, 


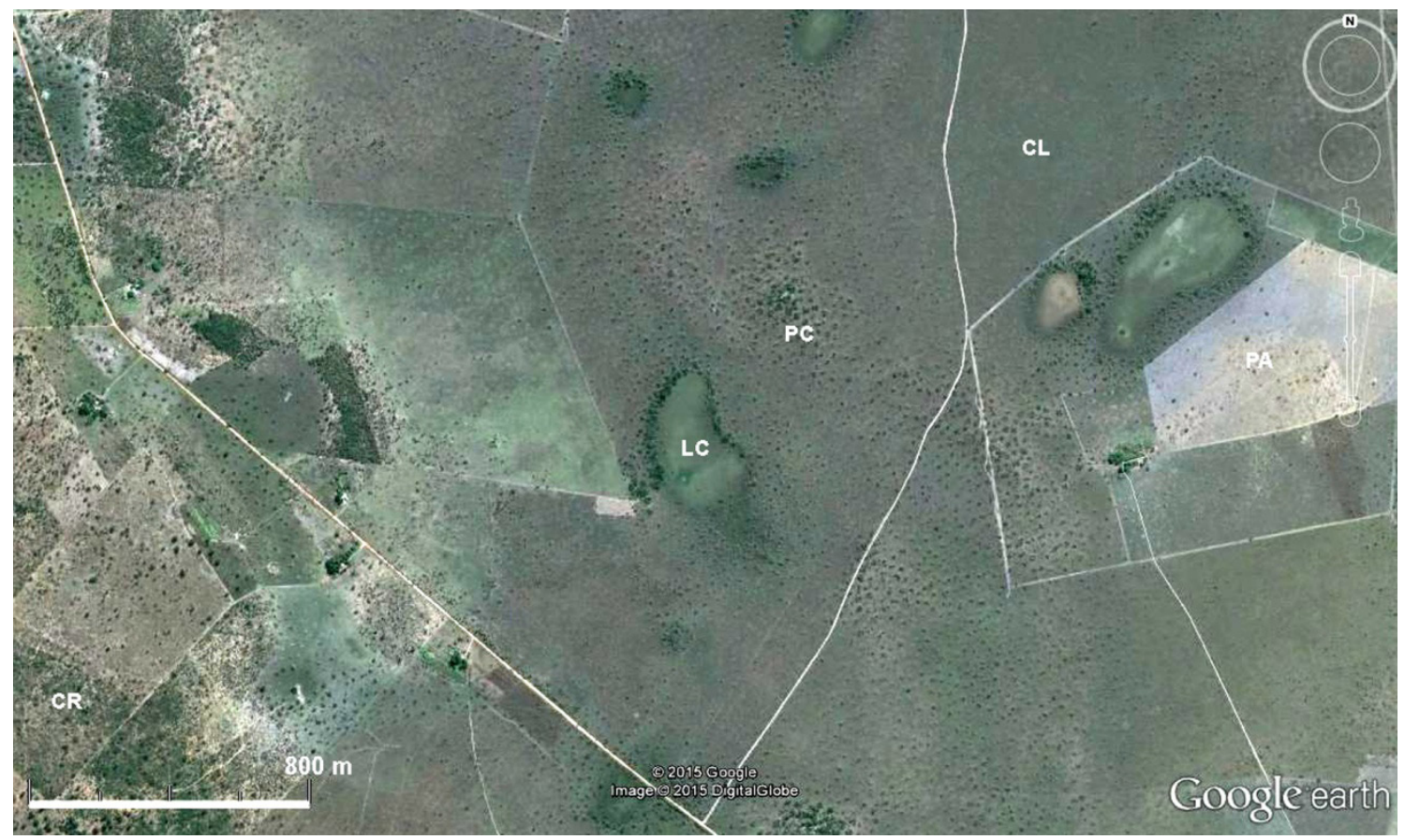

Figura 9. Imagem de satélite extraída do programa Google Earth 7.1.2.2041 (datada de 11/07/2010) mostrando a paisagem onde foram obtidos registros visuais de Blastocerus dichotomus por terceiros na região das Campinas, Fazenda Fruta D'Anta, João Pinheiro. PC) Parque de Cerrado, CL) Campo Limpo, LC) lagoa natural de campina.

fato ocorrido em décadas passadas, quando as populações regionais de $B$. dichotomus teriam sido maiores. Segundo os relatos, a caça seria de cunho esportivo, uma vez que a carne do animal não é apreciada para alimentação. Durante as atividades de campo foram observadas algumas galhadas de machos adultos em residências de caçadores locais, o que confirma a ocorrência da caça e aponta essa atividade como uma ameaça a $B$. dichotomus em João Pinheiro. Salienta-se que não foi possível identificar as localidades exatas de procedência dessas galhadas.

Em relação à população de suçuapara ocorrente na Fazenda Remanso, ao redor da Vereda onde se encontraram os exemplares da espécie há criação de gado bovino em áreas de pastagens, algumas destas contíguas com a formação campestre da Vereda. O íntimo contato do gado com $B$. dichotomus representa risco de transmissão de doenças bovinas. Certamente esse risco aplica-se a outras possíveis populações da espécie na região de João Pinheiro, onde a pecuária é largamente difundida.

$O$ presente registro corresponde à primeira ocorrência confirmada de $B$. dichotomus em João Pinheiro e uma das únicas no Estado de Minas Gerais. Ainda que moradores locais já relatassem a existência do suçuapara, não havia ocorrido um reporte formal para o município. $\mathrm{O}$ local de registro mais setentrional em João Pinheiro situa-se a cerca de $190 \mathrm{~km}$ a sul do limite sul do P. N. Grande Sertão Veredas, área onde também houve ocorrência confirmada da espécie (CHIARELlo et al., 2008).

Como já citado, Chiarello et al. (2008) mencionam que há evidências da ocorrência de B. dichotomus na Fazenda Brejão, no "Triângulo Mineiro". Entretanto, no mesmo trabalho outras 
espécies são relatadas para a Fazenda Brejão, no "Município de Brasilândia de Minas", o qual se situa no Noroeste de Minas Gerais, e não no Triângulo. Há uma Fazenda Brejão em Brasilândia de Minas, localizada a poucos quilômetros a noroeste da FRRP em João Pinheiro, mas no lado oposto do rio Paracatu e abrangendo parte de sua várzea. Então, provavelmente a ocorrência citada por CHIARELLO et al. (2008) referia-se a esta Fazenda Brejão, representada na Figura 10.

Um total de seis localidades foram citadas por AlMEIDA (2011) e CHIARELLo et al. (2008) como áreas de ocorrência de $B$. dichotomus em Minas Gerais, ou ao menos de possível ocorrência, e não foram consideradas nas avaliações sobre o estado de conservação da espécie, as quais referiram-se apenas ao P. N. Grande Sertão Veredas (DUARTE,

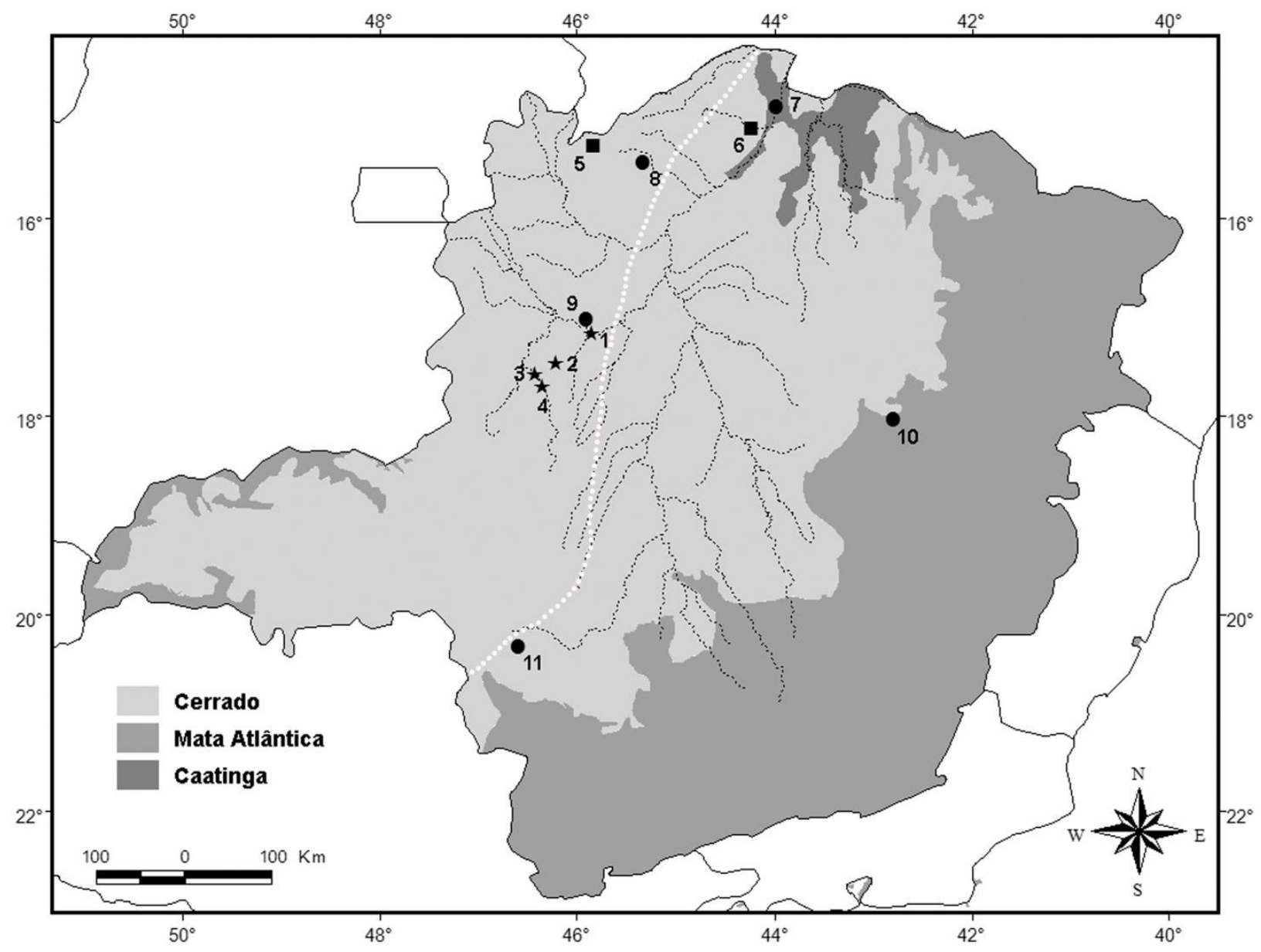

Figura 10. Distribuição geográfica de Blastocerus dichotomus no Estado de Minas Gerais. Estrelas: novos registros em João Pinheiro - 1) Fazenda Remanso na várzea do Rio Paracatu (fotografias de exemplares), 2) Fazenda Fruta D’Anta nas Campinas (relatos de terceiros), 3) Fazenda Claros na várzea do rio da Prata (relatos de terceiros), 4) proximidades da ponte da BR 040 na várzea do rio da Prata (encontro de galhada). Quadrados: registros prévios confirmados: 5) Parque Nacional (P. N.) Grande Sertão Veredas, 6) P. N. Cavernas do Peruaçu (ChIARELlo et al., 2008; DuARTE, 2008; DuARTE et al., 2012a; DuARTE et al., 2012b; IBAMA, 2005; FerReIRA et al., 2011). Pontos: registros prévios a serem confirmados (vide texto): 7) Parque Estadual (P. E.) da Mata Seca, 8) P. E. Serra das Araras, 9) Fazenda Brejão em Brasilândia de Minas, 10) P. E. da Serra Negra, 11) P. N. da Serra da Canastra (ALMEIDA, 2011; CHIARELlo et al., 2008). O tracejado preto indica os rios da bacia do São Francisco. O pontilhado branco (adaptado de DUARTE et al., 2012a) indica o limite oriental da distribuição geográfica potencial de $B$. dichotomus apresentada por DUARTE et al. (2012a). 
2008; DuARTE et al., 2012a; DuARTE et al., 2012b). No presente estudo os registros nessas áreas são considerados como potenciais, em função da carência de evidências, sendo necessária sua confirmação.

As localidades de ocorrência atualmente conhecidas de $B$. dichotomus são representada na Fig. 10. De acordo com os dados anteriormente mencionados, são considerados como confirmados apenas os registros em João Pinheiro (este estudo), no P. N. Grande Sertão Veredas e no P. N. Cavernas do Peruaçu. Em demais localidades os registros foram tratados como a serem confirmados. As localidades de registros em João Pinheiro estão inseridas na distribuição geográfica potencial de $B$. dichotomus apresentada por DUARTE et al. (2012a) (Fig. 10).

\section{DIscussão}

O presente registro com base em fotografias de indivíduos em campo certamente corresponde à ocorrência mais segura da $B$. dichotomus em Minas Gerais, uma vez que demais registros publicados não apresentam as evidências. A maioria dos reportes realizados corresponde a ocorrências na bacia do São Francisco nas porções Norte e Noroeste de Minas Gerais, onde provavelmente persistem as populações mais relevantes da espécie no estado. Em demais regiões de Minas Gerais, há necessidade de confirmações das ocorrências do suçuapara, com base em evidências seguras.

O rio Paracatu e seus afluentes em João Pinheiro abrigam uma grande diversidade de paisagens alagadas em várzeas, as quais podem potencialmente corresponder a áreas de vida de $B$. dichotomus. Esses ambientes são, principalmente, as planícies inundáveis durante as chuvas, as lagoas marginais com suas margens campestres e as Veredas com Campo Limpo Úmido. Nas planícies entre os rios, os ambientes potenciais são as Campinas, com Parque de Cerrado, Veredas e lagoas naturais. Consequentemente, em função da existência desses ambientes, é possível que ainda persistam outros grupos do suçuapara em João Pinheiro, de modo que um inventário torna-se necessário e urgente. Como ambientes semelhantes e, ao menos em parte, contínuos aos de João Pinheiro ocorrem nos municípios vizinhos, especialmente Lagoa Grande, Brasilândia de Minas e Paracatu, inventários na região de entorno também são recomendados.

Em relação às grandes populações conhecidas de $B$. dichotomus, tais como aquelas ocorrentes no Pantanal brasileiro (Mato Grosso e Mato Grosso do Sul), região da Ilha do Bananal no rio Araguaia (Mato Grosso e Tocantins), rio Guaporé (Rondônia) e nas várzeas remanescentes do rio Paraná (Mato Grosso do Sul, Paraná e São Paulo) (DuARTE, 2008; DuARTE et al., 2012a), é possível que a população existente em João Pinheiro seja residual e esteja disjunta daquelas. Estudos de levantamentos faunísticos vêm sendo realizados em João Pinheiro há 15 anos, nos quais grande extensão do município foi vistoriada em expressivas expedições de campo, e não foram obtidas evidências, mesmo que indiretas, de ocorrência do suçuapara em outras áreas externas às campinas e às grandes várzeas do Paracatu e de seus afluentes. Além desses dois tipos de ambientes, não há outros hábitats propícios à ocorrência da espécie no município. Essas informações reforçam 
a possibilidade de tratar-se realmente de uma população residual.

Mesmo que haja grupos do suçuapara em municípios vizinhos, principalmente em Lagoa Grande, Brasilândia de Minas e Paracatu, é possível que os mesmos estejam isolados em função da fragmentação de hábitats, decorrente da intensa atividade agropecuária na região. Entretanto, como há certa conectividade entre as campinas e várzeas desses municípios, também é possível que os grupos regionais de $B$. dichotomus correspondam a uma só população ou metapopulação, mas ainda sim esta continuaria sendo considerada residual em relação às grandes populações da espécie e provavelmente isolada das mesmas.

Foram apontadas, como estratégias para a conservação de $B$. dichotomus, a proteção e recuperação das várzeas, sendo impedida a implantação de grandes empreendimentos agropecuários ou hidrelétricos nos rios onde ainda há populações, e também, que sejam evitadas zonas de contato entre criações de ungulados domésticos e populações de $B$. dichotomus (DUARTE, 2008). Essas estratégias são aplicáveis às áreas úmidas de João Pinheiro que potencialmente podem estar sendo utilizadas como área de vida de indivíduos de $B$. dichotomus. Isto porque parte expressiva das várzeas do rio Paracatu e afluentes encontra-se já alterada e em processo contínuo de degradação, decorrente principalmente de atividades agropecuárias, como observado às margens do Paracatu e dos rios da Prata, Caatinga, Feio, Verde e outros afluentes menores.

Dentre essas atividades, destacam-se as extensas monoculturas às margens do Prata e do Paracatu e na região das Campinas. Nas monoculturas, além da drenagem de alagados naturais para o plantio, há a grande retirada de água dos mananciais para irrigação via pivôs centrais. Atualmente um relevante impacto provém da implantação da monocultura de cana-de-açúcar em larga escala em uma região que abrange tanto a várzea do Paracatu quanto as Campinas, em função da recente implantação de uma usina de álcool. A área mais degradada pelo plantio situa-se a oeste da foz do rio Verde, onde várias lagoas naturais foram destituídas.

Outra atividade, a bovinocultura em larga escala, foi historicamente a maior responsável pelas alterações das várzeas de tais rios, convertidas em pastagens artificiais, além de ter propiciado zonas de contato entre o gado e o suçuapara.

Também contribuíram para as alterações das várzeas as barragens construídas em propriedades rurais, como ocorreu no rio Feio, e impactos futuros são esperados dos previstos represamentos no rio do Sono para empreendimentos hidrelétricos (Pequenas Centrais Hidrelétricas). A implantação desses represamentos está prevista nas proximidades das principais áreas de várzeas do rio do Sono, na região de sua foz com o Paracatu.

A caça ao suçuapara, relatada por moradores mais antigos de João Pinheiro, pode ter sido relevante para a diminuição da população local da espécie no passado. Atualmente, em função do tamanho populacional de $B$. dichotomus possivelmente reduzido, qualquer evento de caça teria elevado potencial de ameaça local à espécie no município. 
Diante das observações apresentadas, é evidente que a população de $B$. dichotomus em João Pinheiro encontra-se sob várias ameaças, as quais, sinergicamente, têm potencial para causar extinção local da espécie. Neste cenário, tornam-se necessárias e urgentes medidas que garantam a proteção dessa população. Indicamos, como medidas a serem adotadas no município de João Pinheiro: 1) a realização de inventário para caracterização da população de $B$. dichotomus localmente existente; 2) a proteção efetiva das várzeas remanescentes, enquanto Áreas de Preservação Permanente (APPs) e, portanto, já prevista em lei; 3 ) a proteção dos remanescentes de Vereda e Campina com lagoas e alagados, também considerando que margens de lagoas são APPs; 4) a inclusão de várzeas, Veredas e áreas pantanosas nas Reservas Legais das propriedades particulares, nos termos da lei; 5) a recuperação das várzeas, Veredas, Campinas e outros alagados que foram degradados, também considerando as APPs; 6) o cercamento ao menos de parte das áreas de vida da espécie, especialmente das reservas legais das propriedades, de modo a impedir a entrada de gado e diminuir seu contato com o suçuapara; 7) a inclusão de pesquisas de detecção, censo e monitoramento de $B$. dichotomus em estudos ambientais para licenciamento de empreendimentos nas áreas com ocorrência potencial da espécie, especialmente as monoculturas de eucalipto e cana-de-açúcar, plantios com irrigação e aproveitamentos hidrelétricos; 8) a inclusão de programas de monitoramento de $B$. dichotomus e programas de recuperação de ambientes de ocorrência potencial da espécie, em ações de mitigação de impactos oriundos de empreendimentos locais; 9) a criação de Unidades de Conservação que protejam áreas significativas de várzeas dos principais rios locais e das Campinas.

Uma vez que no município inexistem Unidades de Conservação, a criação destas destacase como a principal medida a ser tomada. Sugerimos como áreas prioritárias para a criação de Unidades em João Pinheiro: 1) as regiões da várzea do rio da Prata com extensos remanescentes pantanosos conservados, especialmente Veredas e lagoas marginais; 2) regiões da várzea do rio Paracatu, incluindo adjacências do rio Caatinga e do Sono, com extensos remanescentes pantanosos conservados, especialmente Veredas e lagoas marginais; 3) remanescentes das Campinas, especialmente as áreas entre o Paracatu/Prata e o rio Feio, e entre o Feio e o rio Verde (reserva da Fazenda Fruta D’Anta). Além de Unidades de Conservação de Proteção Integral, Reservas Particulares do Patrimônio Natural seriam de relevante importância, uma vez que os locais de registro do suçuapara e demais áreas de possível ocorrência situam-se em propriedades particulares.

Dentre as pesquisas necessárias para a conservação do suçuapara, DUARTE et al. (2012a) destacaram a avaliação da atual distribuição geográfica da espécie, com ênfase nas bacias hidrográficas com potencial hidrelétrico, e a confirmação da ocorrência de populações no P. N. Grande Sertão Veredas. O registro em João Pinheiro vem contribuir com essas duas linhas de pesquisa, ao ampliar a área de distribuição atual da espécie e, ao mesmo tempo, confirmar sua ocorrência no Noroeste de Minas Gerais, região na qual também se insere o P. N. Grande Sertão Veredas.

O registro de $B$. dichotomus em Vereda reforça a importância desse ambiente para a 
manutenção das populações residuais da espécie. Na região de João Pinheiro toda a várzea do rio Paracatu e de seus principais afluentes, os rios da Prata e Caatinga, são acompanhados por Veredas, as quais podem ser pequenas e associadas a nascentes, ou mais extensas e associadas a planícies de inundação.

Blastocerus dichotomus apresentaria hábito primariamente diurno, tal como ocorre no Pantanal onde a espécie não é caçada (DUARTE et al., 2012a). O fato dos registros fotográficos em João Pinheiro terem ocorrido em período noturno, sendo três animais em atividade, possivelmente corrobora o relato de NogueiRA-Neto (1973), acerca do comportamento de $B$. dichotomus tornar-se noturno em locais onde há caça ou perseguição, como ocorrido na planície do rio Paraná. Além da pressão da caça, a simples proximidade do suçuapara com áreas de atividade agropecuária promoveria esta alteração comportamental, por interferência humana indireta.

O registro fotográfico de três indivíduos de $B$. dichotomus em um mesmo local e o relato de outros cinco indivíduos juntos, em João Pinheiro, indicam que a espécie pode formar grupos. Entretanto, apesar de haver observações prévias de formação de grupos familiares (SCHALLER \& VASCONCELLOS, 1978; ToMAs et al., 1997), há possibilidade que tenham sido registradas agregações temporárias, uma vez que foi descrito o comum hábito solitário da espécie (DUARTE et al., 2012a).

\section{CONCLUSÃo}

Há ocorrência confirmada de uma população de Blastocerus dichotomus no Município de João Pinheiro, Noroeste de Minas Gerais, com base em fotografias de exemplares na várzea do rio Paracatu e evidências de ocorrência na várzea do rio da Prata, afluente do primeiro. Alguns indivíduos registrados estão utilizando ambiente de Vereda como área de vida. Considera-se que a população ocorrente em João Pinheiro provavelmente seja residual.

A despeito de não haver um estudo populacional de $B$. dichotomus nessa área, a degradação dos ambientes naturais da várzea do Paracatu e de seus afluentes, as evidências de caça e a presença de bovinos indicam que a população local do suçuapara provavelmente encontra-se ameaçada. Outros impactos em caráter regional que contribuem para ameaça são a expansão da monocultura da cana-de-açúcar nas Campinas e a previsão de represamentos a serem gerados por empreendimentos hidrelétricos no rio do Sono.

Fazem-se necessárias medidas urgentes para a proteção da população de $B$. dichotomus remanescente em João Pinheiro, especialmente a criação de Unidades de Conservação. São apontadas como áreas prioritárias os remanescentes de várzea dos principais rios locais e a região das Campinas.

\section{AgRAdeCIMENTOS}

Agradecemos a Paulo Afonso Dias Silveira, proprietário da Fazenda Remanso do Rio Paracatu, por permitir a realização do estudo na área, aos entrevistados em João Pinheiro, e aos revisores anônimos pelas contribuições ao manuscrito. 


\section{REFERÊNCIAS BIBLIOGRÁFICAS}

\section{AlMEIDA, S. A. C. 2011. Atlas da Fauna em Unidades} de Conservação do Estado de Minas Gerais: Volume 1 - Mastofauna. Belo Horizonte, Instituto Estadual de Florestas, 284 p.

Chiarello, A. G.; Aguiar, L. M. S.; Gregorin, R.; Hirsch, A.; Melo. F. L.; Paglia, A. P. \& Rodrigues, F. H. G. 2008. Mamíferos ameaçados de extinção em Minas Gerais. In: Drummond, G. M.; MAChado, A. B. M.; MARTINS, C. S.; MENDONÇA, M. P. \& StehMANN, J. R. (eds.). Listas Vermelhas das Espécies da Fauna e da Flora Ameaçadas de Extinção em Minas Gerais. Belo Horizonte, Fundação Biodiversitas, mídia digital.

COPAM, 2010. Deliberação Normativa Copam $\mathrm{n}$ 은 147, de 30 de abril de 2010: Aprova a Lista de Espécies Ameaçadas de Extinção da Fauna do Estado de Minas Gerais. Belo Horizonte, Conselho Estadual de Política Ambiental. Disponível em: http://www.siam.mg.gov. $\mathrm{br} / \mathrm{sla} /$ download. pdf?idNorma $=13192$. Acessado em: 20/03/2015.

DUARTE, J. M. B. 2008. Blastocerus dichotomus Illiger, 1815, pp. 820-821. In: MACHADO, A. B. M.; Drummond, G. M. \& PAgliA, A. P. (eds.). Livro Vermelho da Fauna Brasileira Ameaçada de Extinção. 2 v. Brasília, Ministério do Meio Ambiente / Belo Horizonte, Fundação Biodiversitas, $907 \mathrm{p}$.

Duarte, J. M. B.; PIOVEzan, U.; ZANetti, E. S.; RAMos, H. G. C.; Tiepolo, L. M.; Vogliotti, A.; OliVeira, M. L.; Rodrigues, L. F. \& AlmeidA, L. B. $2012 a$.
Avaliação do risco de extinção do cervodo-pantanal Blastocerus dichotomus Illiger, 1815, no Brasil. Biodiversidade Brasileira 2 (3): 3-14.

Duarte, J. M. B.; Piovezan, U.; Zanetti, E. S. \& RAMOS, H. G. C. 2012b. Cervo-do-pantanal (Blastocerus dichotomus), pp. 29-43. In: DuArte, J. M. B. \& ReIS, M. L. Plano de Ação Nacional para a Conservação dos Cervídeos Ameaçados de Extinção. Brasília, Instituto Chico Mendes de Conservação da Biodiversidade, $127 \mathrm{p}$.

Ferreira, G. B.; Oliveira, M. J. R.; MORAES JUNiOR, E. A.; Silva, J. A. \& Rodrigues, F. H. G. 2011. Mamíferos de médio e grande porte do Parque Estadual Veredas do Peruaçu: riqueza, composição e estratégia de conservação. MG. Biota 4(2): 6-19.

IBAMA, 2005. Plano de Manejo: Parque Nacional Cavernas do Peruaçu. v. 1, encarte 2. Brasília, Institudo Brasileiro do Meio Ambiente e dos Recursos Naturais Renováveis, X+134 p.

MMA. 2003. Instrução Normativa $n$ o 003, de 26 de maio de 2003: Lista Nacional das Espécies da Fauna Brasileira Ameaçadas de Extinção. Brasília, Ministério do Meio Ambiente. Disponível em: http://www. icmbio.gov.br/sisbio/images/stories/ instrucoes_normativas/IN_03_2003_ MMA_FaunaAmeacada.pdf. Acessado em: 20/03/2015.

MMA. 2014. Portaria no 444, de 17 de dezembro de 2014: Anexo 1: Lista Nacional Oficial de 
Espécies da Fauna Ameaçadas de Extinção. Brasília, Ministério do Meio Ambiente. Disponível em: http://www.icmbio.gov. $\mathrm{br} /$ portal/images/stories/biodiversidade/ fauna-brasileira/avaliacao-do-risco/ PORTARIA_N\%C2\%BA_444_DE_17_DE_ DEZEMBRO_DE_2014.pdf. Acessado em: 20/03/2015.

Nogueira-Neto, P. 1973. A Criação de Animais Indígenas Vertebrados. São Paulo, Tecnapis, $327 p$.

Pinder. L. \& GROSSE, A. P. 1991. Blastocerus dichotomus. Mammalian Species 380: 1-4.

Piovezan, U.; TIePolo, L. M.; TOMAS, W. M.; Duarte, J. M. B.; VARELA, D. \& MARINHo Filho, J. S. 2010. Marsh deer Blastocerus dichotomus (Illiger, 1815), pp. 66-76. In: DUARTE, L. M. B. \& GonZÁLES, S. (eds.). Neotropical Cervidology: biology and medicine of Latin American Deer. Jaboticabal, Funep/IUCN, 393 p.

RibeIRO, J. F. \& B. M. T. WALTER. 1998. Fitofisionomias do bioma Cerrado, pp. 89-166. In: SANO, S. M. \& S. P. ALMEIDA (eds.). Cerrado: ambiente e flora. Planaltina, Embrapa, xii+556 p.

SChalleR, G. B. \& VAsconcellos, J. M. 1978. A mash deer census in Brazil. Oryx 14: 345-351.

Tiepolo, L. M. \& Tomas, W. M. 2006. Ordem Artiodactyla, pp. 283-303. In: REIS, N. R.; Peracchi, A. L.; Pedro, W. A. \& Lima, I. P. (eds.). Mamíferos do Brasil. Londrina, Nelio R. dos Reis. 437 p.

TOMAS, W. M \& SALIS, S. M. 2000. Diet of the marsh deer (Blastocerus dichotomus) in the Pantanal wetland, Brazil. Studies on Neotropical Fauna and Environment 35: 165-172.

TOMAS, W. M.; BECCACECI, M. D. \& PINDER, L. 1997. Cervo-do-Pantanal (Blastocerus dichotomus), pp. 24-40. In: DUARTE, J.M.B. (ed.). Biologia e Conservação de Cervídeos Sul Americanos: Blastocerus, Ozotoceros e Mazama. Jaboticabal, FUNEP, $238 \mathrm{p}$. 